\title{
FAKTOR-FAKTOR YANG BERHUBUNGAN DENGAN KEJADIAN ISPA PADA BALITA DI WILAYAH KERJA PUSKESMAS TAMMERO'DO KEC. TAMMERO'DO KAB. MAJENE TAHUN 2017
}

\section{Factors Related To the Occurrence of ISPA in Toddler in The Working Area of Puskesmas Tammero'do in 2017}

\author{
Urwatil Wusqa Abidin \\ Universitas Al-Asy'ariyah Mandar \\ (urwaabidin95169@gmail.com)
}

\begin{abstract}
ABSTRAK
Tujuan dalam penelitian untuk mengetahui faktor-faktor yang berhubungan dengan kejadian ISPA pada balita.Penelitian ini mengunakan survey analitik dengan pendekatan Cross Sectional Study. Besar sampel dalam penelitian ini sebanyak 90 responden yang diperoleh dengan metode Purposive Sampling dan diuji dengan menggunakan uji Fisher's Exact Test. Berdasarkan analisis data dapat disimpulkan bahwa ada hubungan antara ISPA dengan pengetahuan ibu $(\mathrm{p}=0,000)$, ISPA dengan status ekonomi $(\mathrm{p}=0,001)$ dan ISPA dengan ventilasi $(\mathrm{p}=0,000)$. Disarankan kepada petugas kesehatan agar dilakukannya penyuluhan mengenai pengetahuan terhadap ibu balita tentang bagaimana cara mencegah terjadinya ISPA.
\end{abstract}

Kata kunci : ISPA, pengetahuan ibu, status ekonomi, dan ventilasi

\begin{abstract}
The purpose of the study to determine the factors associated with the incidence of ARI in infants. This research uses analytical survey with Cross Sectional Study approach. Sample size in this study as many as 90 respondents obtained by Purposive Sampling method and tested by using Fisher's Exact Test. Based on data analysis, it can be concluded that there is a relationship between ISPA with maternal knowledge $(p=0,000)$, ISPA with economic status $(p=0,001)$ and ISPA with ventilation $(p=0,000)$. Suggested to health officer to do counseling about knowledge to mother of balita about how to prevent the occurrence of ISPA.
\end{abstract}

Keywords: ISPA, maternal knowledge, economic status, and ventilation 


\section{PENDAHULUAN}

ISPA adalah saluran pernapasan akut yang merupakan penyebab utama morbiditas dan mortalitas di dunia yang dapat menimbulkan berbagai penyakit tanpa gejala, infeksi ringan sampai penyakit yang parah dan mematikan.Hampir empat juta orang meninggal akibat ISPA setiap tahun, 98\% disebabkan oleh infeksi saluran pernafasan bawah. Kejadian ISPA pada bayi, anak dan orang lanjut usia tergolong tinggi terutama di negara-negara yang pendapatan rendah dan menengah. ISPA juga merupakan salah satu penyakit yang banyak pada rawat inap di sarana pelayanan kesehatan terutama pada bagian perawatan anak. $^{1}$

Penyakit Infeksi Saluran Pernapasan Akut (ISPA) merupakan salah satu masalah kesehatan utama di Indonesia. Kematian akibat pneumonia yang sebagai penyebab utama ISPA di Indonesia mencapai lima kasus di antara 1.000 bayi/balita meninggal tiap tahun dan 12.500 korban per bulan atau 416 kasus sehari atau 17 anak per jam atau seorang bayi tiap lima menit. Oleh karena itu Direktural Jenderal Pemberantasan Penyakit Menular dan Penyehatan Lingkungan (P2
ISPA) lebih memfokuskan pada upaya penanggulangan penyakit ISPA pada anak.

Infeksi Saluran Pernapasan Akut (ISPA) adalah proses infeksi akut berlangsung selama 14 hari, yang disebabkan oleh mikroorganisme yang menyerang salah satu bagian saluran napas, mulai dari hidung (saluran atas) hingga alveoli (saluran bawah), termasuk jaringan adneksanya, seperti sinus, rongga telinga tengah dan pleura. ${ }^{2}$

Pengetahuan ibu tentang penyakit ISPA adalah modal utama terbentuknya kebiasaan yang baik untuk kesehatan anak. Pengetahuan atau kognitif merupakan domain penting untuk terbentuknya tindakan seseorang (overt behavior), ibu yang memiliki pengetahuan yang baik tentang ISPA akan membawa dampak positif bagi kesehatan anak karena resiko kejadian ISPA pada anak dapat dieliminasi seminimal mungkin. ${ }^{3}$

Aktifitas balita lebih sering dilakukan di dalam rumah seperti bermain bersama anggota keluarga, sedangkan lingkungan dalam rumah dapat menyebabkan ISPA pada balita (Lindawati disitasi oleh Fillacano, 2012).Salah satu faktor lingkungan fisik rumah yang dapat 
menyebabkan ISPA yaitu keberadaan ventilasi rumah. Berdasarkan Peraturan $\begin{array}{lll}\text { Mentri Kesehatan No. } & \text { Non }\end{array}$ 1077/MENKES/PER/V/2011, setiap rumah wajib memiliki ventilasi minimal $10 \%$ dari luas rumah. Ventilasi pada rumah yang tidak memenuhi syarat berisiko terserang ISPA 5,125 kali besar dibandingkan dengan rumah dengan ventilasi yang memenuhi syarat. ${ }^{4}$

Berdasarkan data dari Profil Kesehatan Indonesia tahun 2010, ISPA termasuk salah satu dari 10 penyakit terbanyak pada balita rawat jalan di rumah sakit. Daftar Tabulasi Dasar (DTD) menunjukkan bahwa ada 291.356 kasus ISPA balita, pada laki- laki berjumlah 147.410 kasus dan perempuan 143.946 kasus. Untuk pasien rawat inap laki-laki berjumlah 9.737 kasus dan perempuan 8.181 kasus, yang meninggal ada 589 balita dengan presentase $3,29 \%$ dan pada kunjungan rawat jalan sebanyak 433.354 kasus. 5

Provinsi Sulawesi Barat khususnya di Kabupaten Majene jumlah penderita ISPA pada balita di seluruh Puskesmas Kabupaten Majene pada tahun 2015 berjumlah 11.833 balita, kemudian menurun tahun 2016 berjumlah 6.101 balita, dan pada tahun 2017 dari bulan Januari-april berjumlah 1.823 balita. Masyarakat yang banyak terkena ISPA adalah balita dan anak-anak. Begitu juga dengan kasus penderita ISPA di Wilayah Kerja Puskesmas Tammero'do tahun 2015 mencapai 125 balita, kemudian meningkat pada tahun 2016 berjumlah 270 balita, dan dari bulan Januari-April tahun 2017 berjumlah 59 penderita ISPA pada balita.

\section{METODE PENELITIAN}

Jenis penelitian yang digunakan adalah survey analitik dengan pendekatan "cross sectional study" yaitu suatu survei analitik yang mencakup hubungan antara faktor risiko (paparan).Jenis penelitian ini digunakan untuk mengetahui faktor - faktor yang berhubungan dengan kejadian ISPA pada balita di wilayah kerja Puskesmas Tamme'rodo Kecamatan Tammero'do Kabupaten Majene. Penelitian ini dilaksanakan mulai tanggal 03 Februari - 20 April 2017. populasi dalam penelitian ini adalah semua balita yang ada di wilayah kerja Puskesmas Tammero'do sebanyak 112 balita dan sampel sebanyak 90 penderita ISPA di Wilayah Kerja Puskesmas Tammero'do. Dengan tehnik pengambilan 
sampel dilakukan secara non random (non probability) melalui tehnik Purposive Sampling. Data primer diperoleh dikumpulkan melalui wawancara secara langsung dengan ibu balita dengan berkunjung kerumah masing-masing responden dan data sekunder diperoleh dari Puskesmas Tammero'do Kecamatan Tammero'do Kabupaten Majene adalah data penderita ISPA pada balita bulan Januari April tahun 2017

\section{HASIL DAN PEMBAHASAN}

Hasil penelitian menunjukkan bahwa dari 90 responden yang diteliti, sebanyak 62 orang $(68,9 \%) \quad$ responden yang memilikipengetahuan rendah terdapat 48 orang $(53,3 \%)$ yang menderita ISPA dan 14 orang $(15,6 \%)$ yang tidak menderita ISPA sedangkan responden yang memiliki pengetahuan tinggi sebanyak 28 orang $(31,1 \%)$, diantaranya yang menderita ISPA sebanyak 11 orang $(12,2 \%)$ dan 17 orang $(18,9 \%)$ yang tidak menderita ISPA.

Hasil penelitian menunjukkan bahwa dari 90 responden yang diteliti diperoleh sebanyak 46 responden $(51,1 \%)$ yang memiliki ventilasi yang tidak memadai terdapat 43 orang $(47,8 \%)$ yang menderita
ISPA dan 3 orang $(3,3 \%)$ yang tidak menderita ISPA sedangkan responden yang memiliki ventilasi memadai sebanyak 44 responden $(48,9 \%)$ di antaranya yang menderita ISPA sebanyak 16 orang $(17,8 \%)$ dan 28 orang $(31,1 \%)$ yang tidak menderita.

Hasil penelitian menunjukkan bahwa dari 90 responden yang diteliti diperoleh sebanyak 72 orang $(80,0 \%)$ responden yang memiliki status ekonomi rendah terdapat 53 orang $(58,9 \%)$ yang menderita ISPA dan 19 orang $(21,1 \%)$ yang tidak menderita ISPA sedangkan responden yang memiliki status ekonomi tinggi sebanyak 18 orang $(20,0 \%)$ di antaranya yang menderita ISPA sebanyak 6 orang $(6,7 \%)$ dan 12 orang $(13,3 \%)$ yang tidak menderita ISPAHasil penelitian menunjukkan bahwa dari 90 responden yang diteliti diperoleh sebanyak 46 responden $(51,1 \%)$ yang memiliki ventilasi yang tidak memadai terdapat 43 orang $(47,8 \%)$ yang menderita ISPA dan 3 orang $(3,3 \%)$ yang tidak menderita ISPA sedangkan responden yang memiliki ventilasi memadai sebanyak 44 responden $(48,9 \%)$ di antaranya yang menderita ISPA sebanyak 16 orang $(17,8 \%)$ dan 28 orang $(31,1 \%)$ yang tidak menderita ISPA 


\section{KESIMPULAN}

Ada hubungan antara pegetahuan ibu dengan kejadian ISPA pada balita di Wilayah Kerja Puskesmas Tammerodo Kecamatan Tammerodo Kabupaten Majene Tahun 2017 dengan nilai $\mathrm{p}=0,000$ dengan taraf signifikan $(\mathrm{p}<\alpha)$, Ada hubungan antara status ekonomi dengan kejadian ISPA pada balita di Wilayah Kerja Puskesmas Tammerodo Kecamatan Tammerodo Kabupaten Majene Tahun 2017 dengan nilai $\mathrm{p}=0,001$ dengan taraf signifikan $(\mathrm{p}<\alpha)$, Ada hubungan antara status ekonomi dengan kejadian ISPA pada balita di Wilayah Kerja Puskesmas Tammerodo Kecamatan Tammerodo Kabupaten Majene Tahun 2017 dengan nilai $\mathrm{p}=0,001$ dengan taraf signifikan $(\mathrm{p}<\alpha)$.

\section{DAFTAR PUSTAKA}

1. World Health Organization. Pencegahan Dan pengendalian Infeksi Saluran Pernafasan Akut (ISPA) yang cenderung menjadi epidemic dan pandemic di fasilitasi pelayanan kesehatan. 2007.

2. Maryunani A. Ilmu Kesehatan Anak Dalam Kebidanan. Jakarta: Trans Info Media; 2010.
3. Notoatmodjo.S. Metodologi Penelitian Kesehatan. Jakarta: Rieneka Cipta; 2010.

4. Wahyuti, dan Afandi, AI. Analisis Situasi Masalah Kesehatan Wonosobo Propinsi Jawa Tengah Tahun 2010, Tugas Analisis Situasi. Depok: FKM UI; 2011.

5. Depkes RI. Riset Kesehatan Dasar (Riskesdas) [Serial Online] Available at: http://repository.unhas.ac.id/handle/1234 56789/4602. diakses 2015 jam 13.00 [Diakses 25 Agustus 2015]

6. Depkes RI. Pedoman Tekhnisi Penilaian Rumah Sehat, Jakarta: Direktoral Jenderal Pengendalian Penyakit dan Penyehatan Lingkungan; 2007.

7. Depkes RI, Riset Kesehatan Dasar (Riskesdas) [Serial Online] Available at: http://repository.unhas.ac.id/handle/1234 56789/4602. diakses 2015 jam 13.00 [Diakses 25 Agustus 2015]

8. Kusworo. 2012.Hubungan Antara Peran Orang Tua Dalam Pencegahan ISPA Balita Di Dusun Ngeledokesa Sendang Mulya, Tirtomoyo, Wonogiri.(stikespku.pdf)

9. Kusworo. 2012.Hubungan Antara Peran Orang Tua Dalam Pencegahan ISPA Balita Di Dusun Ngeledokesa Sendang 
Mulya, Tirtomoyo, Wonogiri.(stikespku.pdf)

10. Maryunani. 2010. Ilmu Kesehatan Anak Dalam Kebidanan. Jakarta.Trans Info Media

11. Nurindahyati, I. Lingkungan Fisik Rumah dengan Kejadian ISPA pada Balita di Desa Karangnongko. Klaten : Stikes Muhammadiyah Klaten; 2009.

12. Siti.N, 2013.Gambaran faktor yang mempengaeuhi kejadian ISPA pada anak prasekolah di kampung pemulung tangerang selatan .fkik.pdf (SECURED).

13. WHO. 2012. Under- Five Mortality. (Online)

http://www.who.int/gho/child_health/mo rtality/mortality_under_five_text/en/inde x.html

14. WHO. 2012. Acute Respiratory Infections (Update September 2009). (Online).http://www.who.int/vaccine_res earch/diseases/ari/en/index.html 


\section{LAMPIRAN}

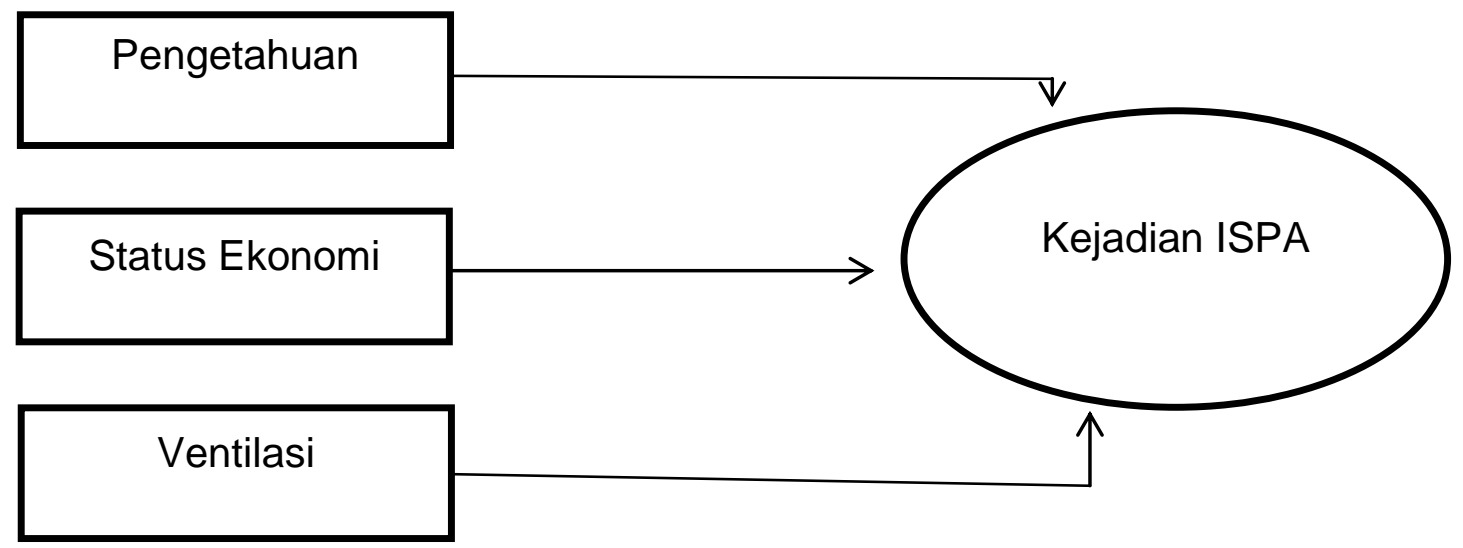

Gambar 1. Kerangka Konsep

Tabel 1. Distribusi Responden Berdasarkan Tingkat Pengetahuan Keluarga di Wilayah Kerja Puskesmas Tammerodo Kec. Tammerodo Kab. Majene

\begin{tabular}{|c|l|c|c|}
\hline No & \multicolumn{1}{|c|}{ Tingkat Pengetahuan } & N & \% \\
\hline 1. & Tinggi & 28 & 31,3 \\
\hline 2. & Rendah & 62 & 68,9 \\
\hline \multicolumn{2}{|c|}{ TOTAL } & 90 & 100 \\
\hline
\end{tabular}

Sumber : Data Primer, 2017

Tabel 2. Distribusi Responden Berdasarkan Status Ekonomi di Wilayah Kerja Puskesmas Tammerodo Kec. Tammerodo Kab. Majene

\begin{tabular}{|c|l|c|c|}
\hline No & \multicolumn{1}{|c|}{ Status Ekonomi } & N & \% \\
\hline 1 & Tinggi & 18 & 20 \\
\hline 2 & Rendah & 72 & 80 \\
\hline \multicolumn{2}{|c|}{ TOTAL } & 90 & 100 \\
\hline
\end{tabular}

Sumber Data : Data Primer, 2017 
Tabel 3. Responden Berdasarkan Ventilasi di Wilayah Kerja Puskesmas Tammerodo Kec. Tammerodo Kab. Majene

\begin{tabular}{|c|l|c|c|}
\hline No & \multicolumn{1}{|c|}{ Ventilai } & N & \% \\
\hline 1 & Memenuhi & 44 & 51,1 \\
\hline 2 & Tidak Memenuhi & 46 & 48,9 \\
\hline \multicolumn{2}{|c|}{ TOTAL } & 90 & 100 \\
\hline
\end{tabular}

Sumber Data : Data Primer, 2017

Tabel 4. Distribusi Responden Berdasarkan Status Ekonomi di Wilayah Kerja Puskesmas Tammerodo Kec. Tammerodo Kab. Majene

\begin{tabular}{|c|c|c|c|c|c|c|c|c|}
\hline \multirow[t]{3}{*}{ No } & \multirow{3}{*}{$\begin{array}{c}\text { Status } \\
\text { Ekonomi }\end{array}$} & \multicolumn{4}{|c|}{ Diagnosa Dokter } & \multicolumn{2}{|c|}{ TOTAL } & $\mathrm{P}$ \\
\hline & & \multicolumn{2}{|c|}{ ISPA } & \multicolumn{2}{|c|}{ Tidak ISPA } & & & \multirow{5}{*}{0,001} \\
\hline & & $\mathrm{n}$ & $\%$ & 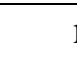 & $\%$ & $\mathrm{~N}$ & $\%$ & \\
\hline 1 & Tinggi & 6 & 6,7 & 12 & 13,3 & 18 & 80 & \\
\hline 2 & Rendah & 53 & 58,9 & 19 & 21,1 & 72 & 20 & \\
\hline & TOTAL & 59 & 65,6 & 31 & 34,4 & 90 & 100 & \\
\hline
\end{tabular}

Sumber Data : Data Primer, 2017

Tabel 5. Distribusi Responden Berdasarkan Ventilasi di Wilayah Kerja Puskesmas Tammerodo Kec. Tammerodo Kab. Majene

\begin{tabular}{|c|c|c|c|c|c|c|c|c|}
\hline \multirow[t]{3}{*}{ No } & \multirow[t]{3}{*}{ Ventilasi } & \multicolumn{4}{|c|}{ Diagnosa Dokter } & \multicolumn{2}{|c|}{ TOTAL } & $\mathrm{P}$ \\
\hline & & \multicolumn{2}{|c|}{ ISPA } & \multicolumn{2}{|c|}{ Tidak ISPA } & & & \multirow{5}{*}{0,000} \\
\hline & & $\mathrm{n}$ & $\%$ & $\mathrm{n}$ & $\%$ & $\mathrm{~N}$ & $\%$ & \\
\hline 1 & Memadai & 16 & 17,8 & 28 & 31,1 & 44 & 48,9 & \\
\hline 2 & $\begin{array}{l}\text { Tidak } \\
\text { Memadai }\end{array}$ & 43 & 47,8 & 3 & 3,3 & 46 & 51,1 & \\
\hline & TOTAL & 59 & 65,6 & 31 & 34,4 & 90 & 100 & \\
\hline
\end{tabular}

Sumber Data : Data Primer, 2017 
Tabel 6. Distribusi Responden Berdasarkan Tingkat Pengetahuan Keluarga di Wilayah Kerja Puskesmas Tammerodo Kec. Tammerodo Kab. Majene

\begin{tabular}{|c|c|c|c|c|c|c|c|c|}
\hline \multirow[t]{3}{*}{ No } & \multirow[t]{3}{*}{ Pengetahuan } & \multicolumn{4}{|c|}{ Diagnosa Dokter } & \multicolumn{2}{|c|}{ TOTAL } & $\mathrm{P}$ \\
\hline & & \multicolumn{2}{|c|}{ ISPA } & \multicolumn{2}{|c|}{ Tidak ISPA } & & & \multirow{5}{*}{0,000} \\
\hline & & $\mathrm{n}$ & $\%$ & $\mathrm{n}$ & $\%$ & $\mathrm{~N}$ & $\%$ & \\
\hline 1 & Tinggi & 11 & 12,2 & 17 & 18,9 & 28 & 31,1 & \\
\hline 2 & Rendah & 48 & 53,3 & 14 & 15,6 & 62 & 68,9 & \\
\hline & TOTAL & 59 & 65,6 & 31 & 34,4 & 90 & 100 & \\
\hline
\end{tabular}

Sumber Data : Data Primer, 2017 